\title{
Erratum to: Agronomic adaptation strategies under climate change for winter durum wheat and tomato in southern Italy: irrigation and nitrogen fertilization
}

\author{
Domenico Ventrella • Monia Charfeddine • \\ Marco Moriondo • Michele Rinaldi • \\ Marco Bindi
}

Published online: 7 January 2012

(C) Springer-Verlag 2012

\section{Erratum to: Reg Environ Change \\ DOI:10.1007/s10113-011-0256-3}

In the original publication of this article, there was a mistake in the second sentence of the abstract section. The correct form of second sentence of the abstract should read as:

"In this study, the cropping system models CERES-Wheat and CROPGRO-Tomato of the Decision Support System for Agrotechnology Transfer (DSSAT) were used to analyse the response of winter durum wheat and tomato crops to climate change, irrigation and nitrogen fertilizer managements in one of most productive areas of Italy (i.e., Capitanata, Puglia)."

The online version of the original article can be found under doi:10.1007/s10113-011-0256-3.

D. Ventrella $(\bowtie) \cdot$ M. Charfeddine $\cdot$ M. Rinaldi Consiglio Per la ricerca e la sperimentazione in agricoltura, Unità di ricerca per i sistemi colturali degli ambienti caldo-aridi (CRA-SCA), Via Celso Ulpiani 5, 70125 Bari, Italy

e-mail: domenico.ventrella@entecra.it

M. Moriondo

CNR-IBIMET, Via G. Caproni 8, 50145 Florence, Italy

M. Bindi

Department of Plant, Soil and Environmental Science,

University of Florence, Piazzale delle Cascine 18,

50144 Firenze, Italy 